\title{
THE LICHEN COLLECTION OF ANDRÁS HORÁNSZKY IN THE HUNGARIAN NATURAL HISTORY MUSEUM
}

\author{
László Lő Kös ${ }^{1}$, Nóra VARGA ${ }^{2}$ and Edit FARKAS ${ }^{2}$ \\ ${ }^{1}$ Department of Botany, Hungarian Natural History Museum, \\ H-1431 Budapest, Pf. 137. Hungary; lokos.laszlo@nhmus.hu \\ ${ }^{2}$ Institute of Ecology and Botany, MTA Centre for Ecological Research, \\ Hungarian Academy of Sciences, H-2163 Vácrátót, Alkotmány u. 2-4. Hungary
}

Lőkös, L., Varga, N. \& Farkas, E. (2016): The lichen collection of András Horánszky in the Hungarian Natural History Museum. - Studia bot. hung. 47(1): 213-226.

\begin{abstract}
A total of 100 species of lichen-forming and lichenicolous fungi are enumerated from the small lichen collection of the late botany professor András Horánszky. The 250 specimens donated to the Hungarian Natural History Museum were collected primarily in Hungary and Austria, and secondarily from Germany, Serbia, and Slovenia. These locality records have never been published; many of them are new for the given area, including some legally protected species, e.g. Cladonia arbuscula, C. magyarica, C. rangiferina, Usnea florida, Xanthoparmelia pulvinaris, and two of the lichenicolous fungi, Athelia arachnoidea and Xanthoriicola physciae. Agonimia globulifera is new to Hungary.
\end{abstract}

Key words: Agonimia globulifera, Austria, floristics, herbarium, Hungary, lichen-forming and lichenicolous fungi, protected species

\section{INTRODUCTION}

András Horánszky, a well-known and respected botany professor of the Eötvös Loránd University (Budapest, Hungary), died recently in 2015 at the age of 87. A detailed description on his scientific career and his bibliography are available in his obituary published recently (SIMON and Csontos 2016).

He was a student of the famous professor, Gábor Andreánszky. He graduated as a biology-geography teacher and worked in his whole life in the same department and university. He was interested in the taxonomy of Poaceae species (especially species of Festuca). As a novel approach, he applied quantitative numerical methods mostly for anatomical characters of the epidermis. He also participated in the phytosociological mapping project of the Bükk and the Zemplén Mts. His most important scientific work is the coenological monograph on the forest communities of the Szentendre-Visegrád Mts (HoRÁNSZKY 1964). Later he paid special attention to the rare and protected plant species, Ferula sadleriana and Linum dolomiticum, and made big efforts for the protection and maintenance of their habitats. 
All the above investigations required a considerably extended field work, in the course of which he collected lots of voucher specimens and established also a private herbarium. He spent also hundreds of field days together with his students in university field excursions in different parts of Hungary.

Some years after his retirement, the university had to move to another place. At that time (between 1997 and 2000) he donated his herbarium (incl. a small lichen collection) to the Hungarian Natural History Museum. Since these records have never been published, our aim is to give an overview on his lichen collection of $c a 250$ specimens, partly identified by him.

\section{MATERIAL AND METHODS}

The specimens are deposited in the Hungarian Natural History Museum, Budapest (Hungary) (BP). Morphological-anatomical investigations and spot tests (ORANGE et al. 2010) were carried out by standard methods using Olympus SZX-7 binocular dissecting microscope and Olympus CX-41 stereomicroscope. For the identification of chemical substances of critical taxa, standard HPTLC methods with solvent system C were carried out (ARUP et al. 1993). For identifications, mainly SMITH et al. (2009) and WIRTH et al. (2013) were used. Nomenclature follows mostly Index Fungorum (CABI 2016) and MycoBank (RoBERT et al. 2016). The locality maps (of collectings) were prepared using the computer program for geographical information system, Quantum GIS (QGIS 2.14 Essen, 2016) based on the central European grid system of $5 \mathrm{~km} \times 6 \mathrm{~km}$ units (BORHIDi 1984, NiKLFELD 1971).

\section{RESULTS AND DISCUSSION}

\section{List of lichens of András Horánszky}

Species are listed in alphabetical order. Locality names are given as they are originally on the labels. Unfortunately, locality information is not very detailed in several cases. Labels were prepared by Horánszky using a matrix printer. Some examples of these printed labels together with some examples of his handwriting are given in Figure 1. Parasitic lichenicolous fungi are marked by an exclamation $\operatorname{sign}(!)$.

Acarospora cervina A. Massal. - Pilis, Kesztölc, Fehér-szirt. Leg.: Horánszky, A., 1973.10.30. [BP 92405].

Acarospora fuscata (Nyl.) Th. Fr. - Visegrádi-hegység, Pomáz, Kőhegy. Leg.: Horánszky, A., 1954.08.26. [BP 92356]. 


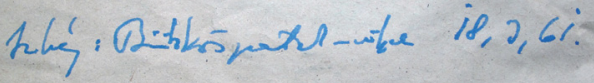
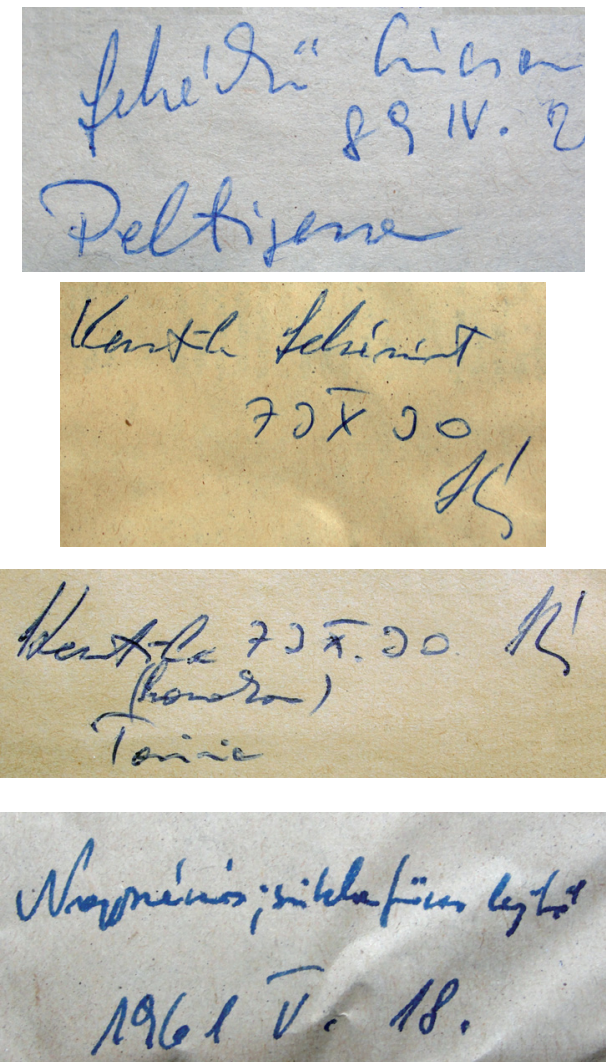

6i. III. 26 Pizre Uyérfile kelingè

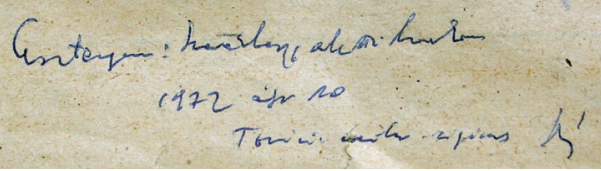

Visegrádi-hgs. Esztergom: Szamárhegy 1952 jun. 6

Legit Horánszky A:

Det:

Fig. 1. Original handwriting of A. Horánszky and printed labels. 
Agonimia globulifera M. Brand et Diederich - Mátra, Sirok, Nyirjes. Leg.: Horánszky, A., 1994.07.01. [BP 96119, together with Cladonia sp.]. - New to Hungary!

Amandinea punctata (Hoffm.) Coppins et Scheid.- Bükk hegység, Bükkszentlászló, enyves éger kérgen. (+ Lecanora carpinea, Lecidella elaeochroma, Melanelixia glabratula). Leg.: Horánszky, A., 1950.11.17. [BP 92333].

Arthonia sp. - Ausztria: Stájer, Palfau, gyertyános-tölgyesben (Salza völgye). Leg.: Horánszky, A., 1993.07.31. [BP 96176].

Aspicilia sp. (cf. caesiocinerea) - Visegrádi-hegység, Pomáz, Kőhegy. Leg.: Horánszky, A., 1954.08.26. [BP 92355].

(!) Athelia arachnoidea (Berk.) Jülich - Budapest, Zugliget, Aesculus fák kérgén. Leg.: Horánszky, A., 1992.07.20. [BP 96125].

Bilimbia lobulata (Sommerf.) Hafellner et Coppins - Pilis, Kesztölc, Fehér-szirt. (+ Toninia sp.). Leg.: Horánszky, A., 1973.10.30. [BP 92402, together with Cladonia magyarica].

Bilimbia sabuletorum (Schreb.) Arnold - Bükk hegység, Lillafüred felett, Fehér-kő-lápa. Leg.: Horánszky, A., 1989.04.21. [BP 92357, together with Cladonia chlorophaea].

Buellia disciformis (Fr.) Mudd - Bükk hegység, Fehér-kő-lápai turistaháznál Lillafüred felett. Leg.: Horánszky, A., 1950.11.17. [BP 92330]. - Bükk hegység, Fehér-kő-lápai turistaháznál Lillafüred felett. (+ Lecanora carpinea, Melanelixia glabratula, Parmelia sulcata, Scoliciosporum chloroccocum). Leg.: Horánszky, A., 1950.11.17. [BP 92331].

Caloplaca aurantia (Pers.) Hellb. - Pilis, Kesztölc, Fehér-szirt. Leg.: Horánszky, A., 1973.10. 30. [BP 92406].

Candelariella vitellina (Hoffm.) Müll. Arg. - Visegrádi-hegység, Vadállókövek Dömös felett. (sub Parmelia isidiata) (+ Physcia caesia, Lecanora argopholis). Leg.: Horánszky, A. (54/28), 1954.08.09. [BP 92351, together with Xanthoparmelia conspersa].

Catapyrenium squamulosum (Ach.) Breuss - Pilis-hegység, Kesztölc, Kétágúhegy. (+). Leg.: Horánszky, A., 1955.05.17. [BP 92350, together with Toninia sedifolia].

Catillaria sp. - Ausztria: Stájer, St. Johann b. Herberstein. Fieberbründl felé, telepített nyáras, fakérgen. (+ Lecidella). Leg.: Horánszky, A., 1993.05.25. [BP 96199, together with Lecanora sp.].

Cetraria islandica (L.) Ach. - Ausztria: Stájer, Palfau mellett a Salza völgyében, elegyes erdőben. Leg.: Horánszky, A., 1993.07.31. [BP 96179]. - Ausztria: Stájer, Murau mellett az erdőhatár felett. Leg.: Horánszky, A., 1993.07.30. [BP 96158]. - Ausztria: Stájer, a Rotmoos lápjain. Leg.: Horánszky, A., 1993.08.01. [BP 96170]. - Németország: Harz-hegység, Brocken, Goethe-Moor. Leg.: Horánszky, A., 1962.07.22. [BP 96142].

Cetrelia monachorum (Zahlbr.) W. L. Culb. et C. F. Culb. - Ausztria: Stájer, Palfau mellett, elegyes erdőben. Leg.: Horánszky, A., 1993.07.31. [BP 96152, BP 96153, BP 96154].

Cladonia arbuscula (Wallr.) Flotow emend. Ruoss - Barcs: telepített erdeifenyvesben. (sub Cl. silv. cf.). Leg.: Horánszky, A., 1975.11.05. [BP 92306]. - Visegrád, Visegrádi-hegység, Hubertuszkunyhó gerince, a Keserűs-hegyen. (sub C. rangiferina). Leg.: Horánszky, A. (54/48), 1954.08.14. [BP 92365].

Cladonia cenotea (Ach.) Schaerer - Zempléni-hegység, Gönc, Dobogó-hegy. Leg.: Horánszky, A., 1955.09.22. [BP 92325].

Cladonia chlorophaea (Sommerf.) Sprengel - Borsodi Bükk hegység, Miskolc, Tatár-árok. (sub Cladonia pyxidata). Leg.: Horánszky, A., 1950.11.17. [BP 96117]. - Bükk hegység, Lillafüred felett, Fehér-kő-lápa. (+ Bilimbia sabuletorum). Leg.: Horánszky, A., 1989.04.21. [BP 92357]. - Pécs, Tubes. Leg.: Horánszky, A., 1963.05.29. [BP 92432]. - Pilisszántó felett a Szentkereszti tető fenyvesében. Leg.: Horánszky, A., 1973.10.30. [BP 92431]. - Visegrádi-hegység, Pilismarót, Hamvas-kő. Leg.: Horánszky, A., 1959.09.06. [BP 92322]. - Visegrádi-hegység, Szentendre (Izbég), Bükkös-patak völ- 
gye. (sub Cladonia). Leg.: Horánszky, A., 1961.03.18. [BP 96121]. - Észak-Németország: Stralsund, Schmale Heide. (sub Cladonia). (+ C. cf. subulata). Leg.: Horánszky, A., 1961.07.27. [BP 96140].

Cladonia coccifera (L.) Willd. - Ausztria: Stájer, Murau mellett erdei úton. Leg.: Horánszky, A., 1993.07.31. [BP 96169].

Cladonia coniocraea (Flörke) Sprengel - Budai-hegység, Hársbokorhegy, Budakeszi felett. (+ C. chlorophaea). Leg.: Horánszky, A., 1989.05.22. [BP 92328]. - Kecskemét: Méntelek, fatuskón. (sub Cladonia). Leg.: Horánszky, A., 1993.06. [BP 92387]. - Visegrádi-hegység, Dömös, Rám-hegy. (sub C. coniocraea f. subulata). Leg.: Horánszky, A. (54/37), 1954.08.10. [BP 92309, BP 92310]. - Visegrádi-hegység, Hubertuszkunyhó gerince, a Keserűs-hegyen. Leg.: Horánszky, A. (54/48), 1954.08.14. [BP 92369]. - Visegrádi-hegység: Szentendre, Bükkös-patak völgye. (sub Cladonia). Leg.: Horánszky, A., 1951.03.22. [BP 96136]. Visegrádi-hegység, Szentendre, Bükkös-patak völgye. (+ C. pyxidata). Leg.: Horánszky, A., 1951.03.22. [BP 92316].

Cladonia convoluta (Lam.) Anders - Barcs, Barcsi Ösborókás Tájvédelmi Körzet. Talajon. Alt.: 100 m a.s.l. Leg.: Horánszky, A., 1963 [BP 92286]. - Barcs, Barcsi Ősborókás Tájvédelmi Körzet. Leg.: Horánszky, A., 1969 [BP 92304]. - Szentmihály-hegy: alsó Stipás szikláknál. (+ Placynthiella icmalea). Leg.: Horánszky, A., 1961.04.11. [BP 92427]. - Szentmihály-hegy: alsó Stipás szikláknál. Leg.: Horánszky, A., 1961.04.11. [BP 92428]. - Csévharaszt. Leg.: Horánszky, A., 1960.05.06. [BP 92434]. - Csévharaszt, Festucetum vaginatae. Leg.: Horánszky, A., 1960.05.06. [BP 92435]. - Csévharaszt, homoki gyepben. (sub Cladonia). Leg.: Horánszky, A., 1966.04.29. [BP 96112]. - Pilis, Kesztölc, Fehér-szirt alatt homokon. (Festucetum vaginatae). (sub Cladonia). Leg.: Horánszky, A., 1973.10.30. [BP 92412]. - Visegrádi-hegység, Esztergom, Strázsahegy alatti homokos területen. Leg.: Sánta, A., Horánszky, A., 1993.07. [BP 92319]. - Visegrádi-hegység, Esztergom, Szamárhegy. Leg.: Horánszky, A., 1972.04.10. [BP 92317]. - Visegrádi-hegység, Szentendre, Macskalyuk. Leg.: Horánszky, A., 1952.06.06. [BP 92324].

Cladonia digitata (L.) Hoffm. - Ausztria: Stájer, Murau mellett az erdőhatár felett. Leg.: Horánszky, A., 1993.07.30. [BP 96177].

Cladonia fimbriata (L.) Fr. - Belső-Somogy, Barcs, Barcsi Ősborókás Tájvédelmi Körzet. Alt.: $100 \mathrm{~m}$ a.s.l. Leg.: Horánszky, A., 1963 [BP 92287]. - Pest megye, Visegrád, Visegrádi-hegység, Hubertuszkunyhó gerince, a Keserűs-hegyen. Leg.: Horánszky, A. (54/48), 1954.08.14. [BP 92368].

Cladonia furcata (Hudson) Schrader - Barcs, Barcsi Ösborókás Tájvédelmi Körzet. Talajon. Alt.: 100 m a.s.l. Leg.: Horánszky, A., 1963 [BP 92288]. - Csévharaszt. Leg.: Horánszky, A., 1960.05.06. [BP 92437, BP 92438]. - Mátra hegység, Mátraszentimre, Ágasvár és Óvár közti nyereg. (sub Cladonia cf. furcata). Leg.: Horánszky, A., 1955.10.07. [BP 92342]. - Visegrádi-hegység, Dobogókő, Szerkövek. Leg.: Horánszky, A. (54/5), 1953.06.02. [BP 92312, BP 92313]. - Visegrádi-hegység, Dömös, Rám-hegy, Gyertyános oldal, Q. Luz. (sub C. furcata var. racemosa). Leg.: Horánszky, A. (54/37), 1954.08.10. [BP 92321]. - Visegrádi-hegység, Leányfalu, Berseg lábánál, Luzulás. Leg.: Horánszky, A., 1953.04.06. [BP 92318]. - Visegrádi-hegység, Szentendre, Óvízvölgy (Sztaravoda-völgy) hársas törmeléklejtő-erdő, Tilio-Frax. (sub Cladonia). Leg.: Horánszky, A. (348), 1955.07.18. [BP 92326]. - Visegrád, Visegrádi-hegység, Hubertuszkunyhó gerince, a Keserüs-hegyen. (sub C. furcata var. racemosa). Leg.: Horánszky, A. (54/48), 1954.08.14. [BP 92367].

Cladonia gracilis (L.) Willd. - Ausztria: Stájer, Palfau, gyertyános-tölgyesben (Salza völgye). Leg.: Horánszky, A., 1993.07.31. [BP 96172].

Cladonia macilenta Hoffm. - Ausztria: Stájer, Palfau mellett, elegyes erdőben. Leg.: Horánszky, A., 1993.07.31. [BP 96160].

Cladonia magyarica Vainio - Csévharaszt. Leg.: Horánszky, A., 1960.05.06. [BP 92436]. Pilis, Kesztölc, Fehér-szirt. (+ Bilimbia lobulata, Toninia sp.). Leg.: Horánszky, A., 1973.10.30. [BP 92402]. - Pilis, Kesztölc, Fehér-szirt alatt homokon. (Festucetum vaginatae). Leg.: Horánszky, A., 1973.10.30. [BP 92413]. - Pilis, Kesztölc, Fehér-szirt alatt homokon. (Festucetum vaginatae). (sub 
Clad. cf. pyx.). Leg.: Horánszky, A., 1973.10.30. [BP 92414]. - Jugoszlávia, a delibláti homokpuszta borókásaiban. Leg.: Horánszky, A., 1965.06.10. [BP 96148].

Cladonia mitis Sandst. - Ausztria: Stájer, Murau mellett az erdőhatár felett. Leg.: Horánszky, A., 1993.07.30. [BP 96165].

Cladonia phyllophora Hoffm. - Ausztria: Stájer, Palfau mellett, elegyes erdőben. Leg.: Horánszky, A., 1993.07.31. [BP 96185].

Cladonia pyxidata (L.) Hoffm. - Visegrádi-hegység, Dobogókő, Szerkövek. (sub C. chlorophaea). Leg.: Horánszky, A. (54/5), 1953.06.02. [BP 92320]. - Visegrádi-hegység, Dömös, Rám-hegy. Leg.: Horánszky, A. (54/37), 1954.08.10. [BP 92311]. - Visegrád, Visegrádi-hegység, Hubertuszkunyhó gerince, a Keserüs-hegyen. (sub C. chlorophaea). Leg.: Horánszky, A. (54/48), 1954.08.14. [BP 92366]. - Ausztria: Stájer, Murau mellett az erdőhatár felett. Leg.: Horánszky, A., 1993.07.30. [BP 96168].

Cladonia rangiferina (L.) F. H. Wigg. - Börzsöny hegység, Nagy Mána-hegy alsó gerinc, a gerinc erdős részén, Antennáriás tisztás. (sub. Cladonia cf. silvatica). Leg.: Horánszky, A., 1990.06.18. [BP 92363]. - Mátra hegység, Mátraszentimre, Ágasvár és Óvár közti nyereg. (sub C. rangiferina). Leg.: Horánszky, A., 1955.10.07 [BP 92343]. - Pest megye, Visegrád, Visegrádi-hegység, Keserűshegy Dömös felett, a Hubertuszkunyhó gerincén. Leg.: Horánszky, A. (54/41), 1954.08.14. [BP 92364]. - Németország: Harz-hegység, Brocken, Goethe-Moor. Leg.: Horánszky, A., 1961.07.22. [BP 96141].

Cladonia rangiformis Hoffm. - Barcs, Barcsi Ösborókás Tájvédelmi Körzet. Talajon. Alt.: $100 \mathrm{~m}$ a.s.l. Leg.: Horánszky, A., 1963 [BP 92290]. - Szentmihály-hegy: alsó Stipás szikláknál. Leg.: Horánszky, A., 1961.04.11. [BP 92426]. - Eger, Bükk hegység, Berva-völgy. (sub Cladonia). Leg.: Horánszky, A., 1950.11.20. [BP 92329]. - Visegrádi-hegység, Esztergom, Szamárhegy. Leg.: Horánszky, A., 1972.04.10. [BP 92314, BP 92315].

Cladonia rei Schaer. - Barcs, Barcsi Ösborókás Tájvédelmi Körzet. Talajon. Alt.: 100 m a.s.l. Leg.: Horánszky, A., 1963 [BP 92291].

Cladonia squamosa Hoffm. - Pilis-hegység, Üröm, Ezüsthegy, hárshegyi homokkő málladékon. Leg.: Horánszky, A., 1955.10.03. [BP 92323].

Cladonia subrangiformis Sandst. - Barcs, Barcsi Ösborókás Tájvédelmi Körzet. Talajon. Alt.: 100 m a.s.l. Leg.: Horánszky, A., 1963 [BP 92289].

Cladonia symphycarpia (Flörke) Fr. - Budai-hegység, Nagyszénás csúcsa mellett. Leg.: Horánszky, A., 1993.08.31. [BP 92417].

Cladonia uncialis (L.) F. H. Wigg. - Budai-hegység, Budapest, Hüvösvölgy, Vadaskert, Hárshegyi homokkő málladékon. Leg.: Horánszky, A., 1953.03.15. [BP 92349].

Cladonia sp. - Szentmihály-hegy: alsó Stipás szikláknál. Leg.: Horánszky, A., 1961.04.11. [BP 92429, BP 92430]. - Csévharaszt. Leg.: Horánszky, A., 1960.05.06. [BP 92439]. - Csévharaszt, homoki gyepben. (sub Cladonia). Leg.: Horánszky, A., 1966.04.29. [BP 92440]. - Mátra, Sirok, Nyirjes. (+ Agonimia globulifera). Leg.: Horánszky, A., 1994.07.01. [BP 96119]. - Visegrádi-hegység: Dömös, Luzulás bükkös. (sub Cladonia). Leg.: Horánszky, A., 1956.08.26. [BP 96137]. - Visegrádi-hegység, Szentendre, Bükkös-patak völgye. Leg.: Horánszky, A., 1951.03.22. [BP 92354]. - Németország: Harz-hegység, Brocken, Goethe-Moor. (sub Cladonia). Leg.: Horánszky, A., 1961.07.22. [BP 96143].

Collema flaccidum (Ach.) Ach. - Bükk hegység, Lusta-völgy. (sub Collema). Leg.: Horánszky, A., 1989.04.19. [BP 96129].

Diploschistes muscorum (Scop.) R. Sant. in Hawksw., James et Coppins - Bükkszenterzsébet, Nagy-kő. Leg.: Horánszky, A., 1975.05.29. [BP 96114].

Evernia prunastri (L.) Ach. - Barcs, Barcsi Ösborókás Tájvédelmi Körzet. (sub cf. Evernia). Leg.: Horánszky, A., 1963 [BP 92295]. - Barcs, Barcsi Ősborókás Tájvédelmi Körzet. Leg.: Horánszky, A., 1969 [BP 92300]. - Börzsöny hegység: Zebegény, Malom-patak völgye, cser kérgén. Leg.: 
Horánszky, A., 1950.11.12. [BP 92425]. - Zempléni-hegység: Erdőbénye. (+ Melanohalea exasperata). Leg.: Horánszky, A., 1950.10.30. [BP 96115].

Flavocetraria cucullata (Bellardi) Kärnefelt et A. Thell - Ausztria: Stájer, Murau mellett az erdőhatár felett. Leg.: Horánszky, A., 1993.07.30. [BP 96159, together with F. nivalis].

Flavocetraria nivalis (L.) Kärnefelt et A. Thell - Ausztria: Stájer, Murau mellett az erdőhatár felett. (+ F. cucullata). Leg.: Horánszky, A., 1993.07.30. [BP 96159].

Flavoparmelia caperata (L.) Hale - Barcs, Barcsi Ösborókás Tájvédelmi Körzet. Leg.: Horánszky, A., 1969 [BP 92305]. - Barcs, Barcsi Ösborókás Tájvédelmi Körzet. Leg.: Horánszky, A., 1993 [BP 92308]. - Ausztria: Stájer, St. Johann b. Herberstein. Fieberbründl felé, telepített nyáras, fakérgen. Leg.: Horánszky, A., 1993.05.25. [BP 96181]

Fulgensia fulgens (Sw.) Elenkin - Nagykovácsi: Nagy-Szénás, sziklafüves lejtő, sziklagyepben. (sub Toninia). Leg.: Horánszky, A., 1961.05.18. [BP 92415]. - Neszmély mellett a védett területen. Leg.: Horánszky, A., 1975.09 [BP 92420]. - Neszmély mellett a védett területen. (+ Psora decipiens). Leg.: Horánszky, A., 1975.05.30. [BP 92419]. - Pilis, Kesztölc, Fehér-szirt alatt homokon. (Festucetum vaginatae). (+ Toninia physaroides). Leg.: Horánszky, A., 1973.10.30. [BP 92409].

Graphis scripta (L.) Ach. - Ausztria: Stájer, Palfau mellett, elegyes erdőben. Leg.: Horánszky, A., 1993.07.31. [BP 96161]. - Ausztria: Stájer, Palfau mellett, elegyes erdőben. (+ Lecanora). Leg.: Horánszky, A., 1993.07.31. [BP 96184]. - Szlovénia: Bohinj. Leg.: Horánszky, A., 1963.06. [BP 96147].

Hypogymnia physodes (L.) Nyl. - Barcs, Barcsi Ösborókás Tájvédelmi Körzet. Leg.: Horánszky, A., 1963 [BP 92293]. - Barcs, Barcsi Ösborókás Tájvédelmi Körzet. Leg.: Horánszky, A., 1969 [BP 92303]. - Barcs, Barcsi Ösborókás Tájvédelmi Körzet. Leg.: Horánszky, A., 1993 [BP 92307]. - Börzsöny hegység: Zebegény, kerítésen. (sub Parmelia physodes). Leg.: Horánszky, A., 1950.11.12. [BP 92424]. - Bükk hegység, Eger, Berva-völgy. Leg.: Horánszky, A., 1950.11.20. [BP 92334]. - Bükk hegység. Lusta-völgy, gyertyános-tölgyes. Bükkfakérgen. Leg.: Horánszky, A., 1989.05.19. [BP 96130]. - Bükk hegység. Lusta-völgy, gyertyános-tölgyes. Bükkfakérgen. (+ Parmelia sulcata). Leg.: Horánszky, A., 1989.05.19. [BP 96131]. - Vác felett a Naszályon, mészkerülő tölgyes, hárshegyi homokkövön (Dicranum longifoliummal). (+ Parmelia saxatilis). Leg.: Horánszky, A. [28.08.1949] [BP 92423]. - Visegrádi-hegység, Leányfalu, Berseg lábánál, Luzulás. (sub Parmelia physodes). Leg.: Horánszky, A., 1953.04.06. [BP 92338]. - Visegrád, Apát-kuti-bérc. Leg.: Horánszky, A., 1961.03.18. [BP 92433]. - Visegrádi-hegység, Szentendre, Lajosforrás feletti lejtő. (sub Parmelia physodes). (+ Parmelia sulcata). Leg.: Horánszky, A., 1953.03.20. [BP 92348]. - Ausztria, a Rotmoos lápjain száraz fenyőágakon. Leg.: Horánszky, A., 1993.09.01. [BP 96145]. Ausztria: Stájer, St. Johann b. Herberstein. Fieberbründl felé, erdeifenyő kérgen. Leg.: Horánszky, A., 1993.05.25. [BP 96207].

Hypogymnia tubulosa (Schaer.) Hav. - Bükk hegység. Lusta-völgy, gyertyános-tölgyes. Bükkfakérgen. (+ Hypogymnia physodes, Parmelia sulcata). Leg.: Horánszky, A., 1989.05.19. [BP 96132].

Lecanora argopholis (Ach.) Ach. - Visegrádi-hegység, Vadállókövek Dömös felett. (sub Parmelia isidiata) (+ Candelariella vitellina, Physcia caesia). Leg.: Horánszky, A. (54/28), 1954.08.09. [BP 92351, together with Xanthoparmelia conspersa].

Lecanora carpinea (L.) Vainio - Bükk hegység, Fehér-kő-lápai turistaháznál Lillafüred felett. Leg.: Horánszky, A., 1950.11.17. [BP 92332].

Lecanora conizaeoides Cromb. - Kecskemét: Méntelek, Pinus kérgen. Leg.: Horánszky, A., 1992.07.15. [BP 92380, BP 92386]. - Kecskemét: Méntelek, Pinus kérgen. (+ Scoliciosporum chlorococcum). Leg.: Horánszky, A., 1992.07.15. [BP 92381]. - Kecskemét: Méntelek, Pinus kérgen. Leg.: Horánszky, A., 1993.06. [BP 92379]. - Pilisszentiván: Kis-Szénás, Fraxinus ornus kérgen. Leg.: Horánszky, A., 1987.06.10. [BP 92418].

Lecanora crenulata Hook. - Pilis, Kesztölc, Fehér-szirt. Leg.: Horánszky, A., 1973.10.30. [BP 92407]. 
Lecanora hagenii (Ach.) Ach. - Kecskemét: Méntelek, telepített nyáras, fakérgen. Leg.: Horánszky, A., 1993.09.06. [BP 92373].

Lecanora rupicola (L.) Zahlbr. - Börzsöny hegység, Zebegény, Szt. Mihály-hegy, Spiraea cserjésben. Leg.: Horánszky, A., 1955.08.30. [BP 92358]. - Visegrádi-hegység, Vadállókövek Dömös mellett. Leg.: Horánszky, A., 1949.08. [BP 96122].

Lecanora sp. - Budapest, Zugliget, Aesculus fák kérgén. Leg.: Horánszky, A., 1992.07.20. [BP 96126]. - Ausztria: Stájer, Palfau mellett, elegyes erdőben. (+ Graphis). Leg.: Horánszky, A., 1993.07.31. [BP 96186]. - Ausztria: Stájer, St. Johan b. Herberstein. (+ Lecidella). Leg.: Horánszky, A., 1992.05.29. [BP 96196]. - Ausztria: Stájer, St. Johann b. Herberstein. Fieberbründl felé, bükk kérgen. Leg.: Horánszky, A., 1993.05.25. [BP 96198]. - Ausztria: Stájer, St. Johann b. Herberstein. Fieberbründl felé, gyertyán kérgen. Leg.: Horánszky, A., 1993.05.25. [BP 96187]. - Ausztria: Stájer, St. Johann b. Herberstein. Fieberbründl felé, tölgy kérgen. (+ Punctelia). Leg.: Horánszky, A., 1993.05.25. [BP 96203]. - Ausztria: Stájer, St. Johann b. Herberstein. Fieberbründl felé, telepített nyáras, erdeifenyő kérgen. Leg.: Horánszky, A., 1993.05.25. [BP 96188]. - Ausztria: Stájer, St. Johann b. Herberstein. Fieberbründl felé, telepített nyáras, fakérgen. Leg.: Horánszky, A., 1993.05.25. [BP 96206]. - Ausztria: Stájer, St. Johann b. Herberstein. Fieberbründl felé, telepített nyáras, fakérgen. (+ Catillaria, Lecanora, Lecidella). Leg.: Horánszky, A., 1993.05.25. [BP 96199]. - Ausztria: Stájer, St. Johann b. Herberstein. Fieberbründl felé, telepített nyáras, fakérgen. (+ Lecanora, Lecidella). Leg.: Horánszky, A., 1993.05.25. [BP 96200]. - Ausztria: Stájer, St. Johann b. Herberstein. Fieberbründl felé, telepített nyáras, fakérgen. (+ Lecanora, Physcia adscendens, Xanthoria parietina). Leg.: Horánszky, A., 1993.05.25. [BP 96201].

Lecidea confluens (Weber) Ach. - Ausztria: Salzburg, Radstadter Tauern. Leg.: s.n., 1862. [BP 96139].

Lecidella elaeochroma (Ach.) M. Choisy - Bükk hegység, Bükkszentlászló, enyves éger kérgen. (+ Amandinea punctata, Lecanora carpinea, Melanelixia glabratula). Leg.: Horánszky, A., 1950.11.17. [BP 92333].

Lecidella sp. - Ausztria: Stájer, Palfau mellett, elegyes erdőben. (+ Lecanora). Leg.: Horánszky, A., 1993.07.31. [BP 96166].

Lobaria pulmonaria (L.) Hoffm. - Ausztria: Stájer, Palfau mellett, elegyes erdőben. Leg.: Horánszky, A., 1993.07.31. [BP 96173].

Melanelia glabra (Schaerer) Essl. - Visegrádi-hegység, Pomáz mellett, Kiscsikóvár. Leg.: Horánszky, A., 1953.03.20. [BP 92337].

Melanelia sp. - Börzsöny hegység, Zebegény, Szt. Mihály-hegy, Tilio-Frax. Leg.: Horánszky, A., 1955.08.30. [BP 92360]. - Ausztria: Stájer, Palfau mellett, elegyes erdőben. Leg.: Horánszky, A., 1993.07.31. [BP 96195]. - Ausztria: Stájer, St. Johann b. Herberstein. Fieberbründl felé, gyertyán kérgen. (+ Phlyctis argena, Graphis). Leg.: Horánszky, A., 1993.05.25. [BP 96197]. - Ausztria: Stájer, St. Johann b. Herberstein. Fieberbründl felé, telepített nyáras, fakérgen. (+ Hafellia). Leg.: Horánszky, A., 1993.05.25. [BP 96192].

Melanelixia glabratula (Lamy) Sandler et Arup - Bükk hegység. Lusta-völgy, gyertyánostölgyes. Bükkfakérgen. Leg.: Horánszky, A., 1989.05.19. [BP 96133].

Melanohalea exasperata (De Not.) O. Blanco, A. Crespo, Divakar, Essl., D. Hawksw. et Lumbsch - Zempléni-hegység: Erdőbénye. Leg.: Horánszky, A., 1950.10.30. [BP 96115, together with Evernia prunastri].

Menegazzia terebrata (Hoffm.) A. Massal. - Ausztria: Stájer, Palfau mellett, elegyes erdőben. Leg.: Horánszky, A., 1993.07.31. [BP 96163]. - Ausztria: Stájer, Palfau mellett, elegyes erdőben. (+ Normandina pulchella). Leg.: Horánszky, A., 1993.07.31. [BP 96162]. - Ausztria: Stájer, Palfau mellett, elegyes erdőben. Leg.: Horánszky, A., 1993.07.31. [BP 96164, together with Pertusaria sp.].

Nephroma parile Ach. - Comit. Heves. In rupibus andesiticis umbrosis montis Ágasvár prope pag. Nagybátony. Alt.: $750 \mathrm{~m}$ a.s.l. Leg.: Boros, Á., 1928.05.06. [BP 92341]. 
Normandina pulchella (Borrer) Nyl. - Ausztria: Stájer, Palfau mellett, elegyes erdőben. Leg.: Horánszky, A., 1993.07.31. [BP 96162, together with Menegazzia terebrata].

Parmelia saxatilis (L.) Ach. - Barcs, Barcsi Ősborókás Tájvédelmi Körzet. Leg.: Horánszky, A., 1969 [BP 92301]. - Visegrád, Visegrádi-hegység, Hubertuszkunyhó gerince, a Keserüs-hegyen. Leg.: Horánszky, A. (54/41), 1954.08.14. [BP 92327].

Parmelia sulcata Taylor - Barcs, Barcsi Ösborókás Tájvédelmi Körzet. Leg.: Horánszky, A., 1963 [BP 92294]. - Barcs, Barcsi Ősborókás Tájvédelmi Körzet. Leg.: Horánszky, A., 1969 [BP 92302]. - Börzsöny hegység, Zebegény, Szt. Mihály-hegy, Tilio-Frax. Leg.: Horánszky, A., 1955.08.30. [BP 92361]. - Kecskemét: Méntelek. Szürkenyár kérgen. (+ Hypogymnia physodes). Leg.: Horánszky, A., 1993.06. [BP 92390]. - Visegrádi-hegység, Kiscsikóvár Pomáz mellett. Leg.: Horánszky, A., 1953.03.20. [BP 92336]. - Ausztria, a Rotmoos lápjain száraz fenyőágakon. Leg.: Horánszky, A., 1993.09.01. [BP 96146]. - Ausztria: Stájer, St. Johann b. Herberstein. Fieberbründl felé, telepített nyáras, fakérgen. Leg.: Horánszky, A., 1993.05.25. [BP 96189]. - Ausztria: Stájer, St. Johann b. Herberstein. Fieberbründl felé, telepített nyáras, fakérgen. (+ Physcia, Physcia, Xanthoria). Leg.: Horánszky, A., 1993.05.25. [BP 96190].

Parmelina tiliacea (Hoffm.) Hale - Börzsöny hegység, Zebegény, Szt. Mihály-hegy, TilioFrax. Leg.: Horánszky, A., 1955.08.30. [BP 92362].

Peltigera horizontalis (Hudson) Baumg. - Mátra hegység, Mátraszentimre, Ágasvár és Óvár közti nyeregben. Leg.: Horánszky, A., 1955.10.07. [BP 92345]. - Visegrád, Visegrádi-hegység, Hubertuszkunyhó gerince, a Keserűs-hegyen. Leg.: Horánszky, A., 1954.08.14. [BP 92335].

Peltigera praetextata (Sommerf.) Zopf - Bükk hegység, Virágostó-lápa. (sub Peltigera). Leg.: Horánszky, A., 1986.04.26. [BP 92353]. - Visegrádi-hegység, Dömös, Lukács-árok. Leg.: Horánszky, A. (13), 1949.04.23. [BP 92340]. - Visegrádi-hegység, Pilismarót, Somos-árok. Leg.: Horánszky, A., 1959.09.06. [BP 92346, BP 92347]. - Visegrádi-hegység, Bükkös-patak völgye Szentendrénél. (sub Peltigera). Leg.: Horánszky, A., 1951.03.22. [BP 92352]. - Visegrádi-hegység, Szentendre (Izbég), Bükkös-patak völgye. (sub Peltigera). Leg.: Horánszky, A., 1961.03.18. [BP 96120]. - Ausztria: Stájer, Palfau mellett, elegyes erdőben. Leg.: Horánszky, A., 1993.07.31. [BP 96151]. - Jugoszlávia, a delibláti homokpuszta borókásaiban. (sub Peltigera canina). Leg.: Horánszky, A., 1965.06.10. [BP 96149].

Peltigera sp. - Bükk hegység: Fehér-kő csúcsa Ceraso-Quercetumában, mészkősziklán. Leg.: Horánszky, A., 1989.04.21. [BP 96134]. - Bükk hegység: Szinva-völgy. Leg.: Horánszky, A., 1950.11.18. [BP 96135]. - Mátra: az Óvár és Ágasvár között, erdőben. (sub Peltigera). Leg.: Horánszky, A., 1955.10.07. [BP 92344]. - Ausztria: Stájer, Palfau mellett a Salza völgyében, elegyes erdőben. Leg.: Horánszky, A., 1993.07.31. [BP 96157].

Pertusaria sp. - Ausztria: Stájer, Palfau mellett, elegyes erdőben. Leg.: Horánszky, A., 1993.07.31. [BP 96178, BP 96194]. - Ausztria: Stájer, Palfau mellett, elegyes erdőben. (+ Menegazzia terebrata). Leg.: Horánszky, A., 1993.07.31. [BP 96167].

Phaeophyscia endophoenicea (Harm.) Moberg - Ausztria: Stájer, Palfau mellett, elegyes erdőben. (+ Physcia adscendens). Leg.: Horánszky, A., 1993.07.31. [BP 96175].

Phaeophyscia orbicularis (Necker) Moberg - Kecskemét: Méntelek. (+ Lecania sp., Physcia tenella). Leg.: Horánszky, A., 1993.06. [BP 92388]. - Kecskemét: Méntelek. Szürkenyár kérgen. Leg.: Horánszky, A., 1993.06. [BP 92393].

Phlyctis argena (Ach.) Flot. - Ausztria: Stájer, Donnersbach-völgy, Acer pseudoplatanus kérgen. Leg.: Horánszky, A., 1986.08.16. [BP 96182].

Physcia adscendens (Fr.) H. Olivier - Kecskemét: Méntelek, telepített nyáras, fakérgen. Leg.: Horánszky, A., 1993.09.06. [BP 92372]. - Kecskemét: Méntelek, szürkenyár kérgen. Leg.: Horánszky, A., 1992.07.15. [BP 92394]. - Ausztria: Stájer, St. Johann b. Herberstein. Fieberbründl felé, telepített nyáras, fakérgen. Leg.: Horánszky, A., 1993.05.25. [BP 96205]. - Ausztria: Stá- 
jer, St. Johann b. Herberstein. Fieberbründl felé, telepített nyáras, fakérgen. (+ Lecanora). Leg.: Horánszky, A., 1993.05.25. [BP 96202].

Physcia caesia (Hoffm.) Fürnr. - Börzsöny hegység, Zebegény, Szt. Mihály-hegy, Tilio-Frax. Leg.: Horánszky, A., 1955.08.30. [BP 92359].

Physcia stellaris (L.) Nyl. - Kecskemét: Méntelek, telepített nyáras, fakérgen. Leg.: Horánszky, A., 1993.09.06. [BP 92371].

Physcia tenella (Scop.) DC. - Kecskemét: Méntelek, telepített nyáras, fakérgen. Leg.: Horánszky, A., 1993.09.06. [BP 92370]. - Kecskemét: Méntelek. Szürkenyár kérgen. (+ Lecania sp.). Leg.: Horánszky, A., 1993.06. [BP 92389].

Physcia sp. - Ausztria: Stájer, St. Johann b. Herberstein. Fieberbründl felé, telepített nyáras, fakérgen. (+ Physcia, Lecanora, Lecidella, Xanthoria). Leg.: Horánszky, A., 1993.05.25. [BP 96191].

Physconia sp. - Ausztria: Stájer, Palfau mellett a Salza völgyében, elegyes erdőben. Leg.: Horánszky, A., 1993.07.31. [BP 96156]. - Ausztria: Stájer, St. Johann b. Herberstein. (+ Lecanora, Lecanora, Lecanora). Leg.: Horánszky, A., 1993.05.29. [BP 96193].

Placynthiella icmalea (Ach.) Coppins et P. James - Szentmihály-hegy: alsó Stipás szikláknál. Leg.: Horánszky, A., 1961.04.11. [BP 92427, together with Cladonia convoluta].

Placocarpus schaereri (Fr.) Breuss - Ehingen ad ... (sub Dermatocarpon monstrosum Mass.). Leg.: Eggler, 1928.08. [BP 96138].

Protoparmeliopsis muralis (Schreber) M. Choisy - Pilis, Kesztölc, Fehér-szirt. Leg.: Horánszky, A., 1973.10.30. [BP 92403, BP 92404, BP 92408]. - Ausztria: Stájer, St. Johann b. Herberstein. Fieberbründl felé, hegyi juhar kérgen. (+ Phaeophyscia orbicularis). Leg.: Horánszky, A., 1993.05.25. [BP 96180].

Pseudevernia furfuracea (L.) Zopf - Barcs, Barcsi Ösborókás Tájvédelmi Körzet. Leg.: Horánszky, A., 1963 [BP 92292, BP 92296]. - Barcs, Barcsi Ösborókás Tájvédelmi Körzet. Leg.: Horánszky, A., 1969 [BP 92299]. - Ausztria: Stájer, a Rotmoos lápjain. Leg.: Horánszky, A., 1993.08.01. [BP 96171]. - Ausztria, a Rotmoos lápjain száraz fenyoágakon. Leg.: Horánszky, A., 1993.09.01. [BP 96144].

Psora decipiens (Hedwig) Hoffm. - Nagykovácsi: Nagy-Szénás, Caricetum humilisben. (+ Fulgensia fulgens). Leg.: Horánszky, A., 1961.05.18. [BP 92416]. - Pilis, Kesztölc, Fehér-szirt. Talajon. Leg.: Horánszky, A., 1973.10.30. [BP 92398, BP 92399, BP 92400].

Punctelia sp. - Ausztria: Stájer, St. Johann b. Herberstein. Fieberbründl felé, tölgy kérgen. Leg.: Horánszky, A., 1993.05.25. [BP 96203, together with Lecanora sp.].

Ramalina farinacea (L.) Ach. - Barcs, Barcsi Ösborókás Tájvédelmi Körzet. (sub cf. Ramalina). Leg.: Horánszky, A., 1963 [BP 92297].

Ramalina pollinaria (Westr.) Ach. - Ausztria: Stájer, Donnersbach-völgy, Acer pseudoplatanus kérgen. Leg.: Horánszky, A., 1986.08.16. [BP 96150].

Scoliciosporum chlorococcum (Stenham.) Vězda - Budapest, Zugliget, Aesculus fák kérgén. Leg.: Horánszky, A., 1992.07.20. [BP 96127]. - Kecskemét: Méntelek, Pinus kérgen. Leg.: Horánszky, A., 1993.06. [BP 92385]. - Kecskemét: Méntelek, Pinus kérgen. (+ Lecanora conizaeoides). Leg.: Horánszky, A., 1992.07.15. [BP 92382, BP 92383, BP 92384]. - Kecskemét: Méntelek, Bázisterület, erdeifenyő kérgen. Leg.: Horánszky, A., 1992.07.15. [BP 92391, BP 92392].

Squamarina cartilaginea (With.) P. James - Pilis, Kesztölc, Fehér-szirt. Talajon. Leg.: Horánszky, A., 1973.10.30. [BP 92401].

Squamarina lentigera (Weber) Poelt - Neszmély mellett a védett területen. Leg.: Horánszky, A., 1975.09 [BP 92422].

Thamnolia vermicularis (Sw.) Schaer. - Ausztria: Stájer, Murau mellett az erdőhatár felett. Leg.: Horánszky, A., 1993.07.30. [BP 96155].

Toninia opuntioides (Vill.) Timdal - Pilis, Kesztölc, Fehér-szirt alatt homokon. (Festucetum vaginatae). (sub Toninia). Leg.: Horánszky, A., 1973.10.30. [BP 92410]. 
Toninia physaroides (Opiz) Zahlbr. - Pilis, Kesztölc, Fehér-szirt. Talajon. (sub cf. Toninia). Leg.: Horánszky, A., 1973.10.30. [BP 92395]. - Pilis, Kesztölc, Fehér-szirt alatt homokon. (Festucetum vaginatae). (+ Fulgensia fulgens). Leg.: Horánszky, A., 1973.10.30. [BP 92411]. - Visegrádi-hegység, Esztergom, Szamárhegy. (sub Toninia coeruleonigricans). Leg.: Horánszky, A., 1972.04.10. [BP 92339].

Toninia sedifolia (Scop.) Timdal - Pilis, Kesztölc, Fehér-szirt. Talajon. (+ Psora decipiens). Leg.: Horánszky, A., 1973.10.30. [BP 92396]. - Pilis-hegység, Kesztölc, Kétágúhegy. (+ Catapyrenium squamulosum). Leg.: Horánszky, A., 1955.05.17. [BP 92350]. - Neszmély mellett a védett területen. (sub Toninia coeruleonigricans). Leg.: Horánszky, A., 1975.09 [BP 92421].

Toninia sp. - Pilis, Kesztölc, Fehér-szirt. Leg.: Horánszky, A., 1973.10.30. [BP 92397].

Usnea florida (L.) F. H. Wigg. - Borsodi Bükk hegység, Eger, Berva-völgy. (sub cf. Usnea). Leg.: Horánszky, A., 1950.11.20. [BP 96118].

Usnea sp. - Barcs Leg.: Horánszky, A., 1963 [BP 92298]. - Zempléni-hegység: Erdőbénye. Leg.: Horánszky, A., 1950.10.30. [BP 96116].

Verrucaria sp. - Ausztria: Stájer, St. Johan b. Herberstein. Kőfalon. Leg.: Horánszky, A., 1992.05.29. [BP 96183].

Xanthoparmelia conspersa (Ach.) Hale - Visegrádi-hegység, Vadállókövek Dömös felett. (sub Parmelia isidiata) (+ Candelariella vitellina, Physcia caesia, Lecanora argopholis). Leg.: Horánszky, A. (54/28), 1954.08.09. [BP 92351].

Xanthoparmelia protomatrae (Gyeln.) Hale - Visegrádi-hegység, Vadállókövek Dömös mellett. Leg.: Horánszky, A., 1949.08. [BP 96123]. - Visegrádi-hegység, Vadállókövek Dömös mellett. (+ Candelariella vitellina). Leg.: Horánszky, A., 1949.08. [BP 96124].

Xanthoparmelia pulvinaris (Gyeln.) Ahti et D. Hawksw. - Vácrátót: a park fölött futóhomokon. Leg.: Fóriss, F. (23871), 1948.09.02. [BP 96128].

Xanthoria parietina (L.) Th. Fr. - Zalaegerszeg, Pózva, nyárfatörzsön. (+ Xanthoriicola physciae). Leg.: Horánszky, A., 1961.03.26. [BP 96113]. - Ausztria: Stájer, Palfau mellett, elegyes erdőben. Leg.: Horánszky, A., 1993.07.31. [BP 96174]. - Ausztria: Stájer, St. Johann b. Herberstein. Fieberbründl felé, telepített nyáras, fakérgen. Leg.: Horánszky, A., 1993.05.25. [BP 96204].

(!) Xanthoriicola physciae (Kalchbr.) D. Hawksw. - Zalaegerszeg, Pózva, nyárfatörzsön. (+). Leg.: Horánszky, A., 1961.03.26. [BP 96113, together with Xanthoria parietina].

\section{Evaluation}

The ca 250 lichen specimens collected by him between 1947 and 1994 consist of 180 Hungarian (72\%) and 70 foreign (28\%) specimens, including considerable amount of duplicates from both areas. The foreign material is mainly from Austria (from alpine areas), and a few from Germany, Serbia, and Slovenia. Hungarian collecting localities are presented on Figure 2. Most of the lichen specimens were collected in the Pilis-Visegrád Mts (Fig. 3). The Bükk, Mátra, and Zemplén Mts are also represented by several specimens, but localities are rather sporadical. The majority of the specimens are terricolous or saxicolous, and just a few were collected from tree bark.

The altogether 100 species are predominantly composed of conspicuous, fruticose, and foliose lichens ( ca 63\%), mainly Cladonias (22 species) and Parmelias (14 species). Many of these locality records are valuable floristical novelties, including some old records of the legally protected Cladonia arbuscula, 


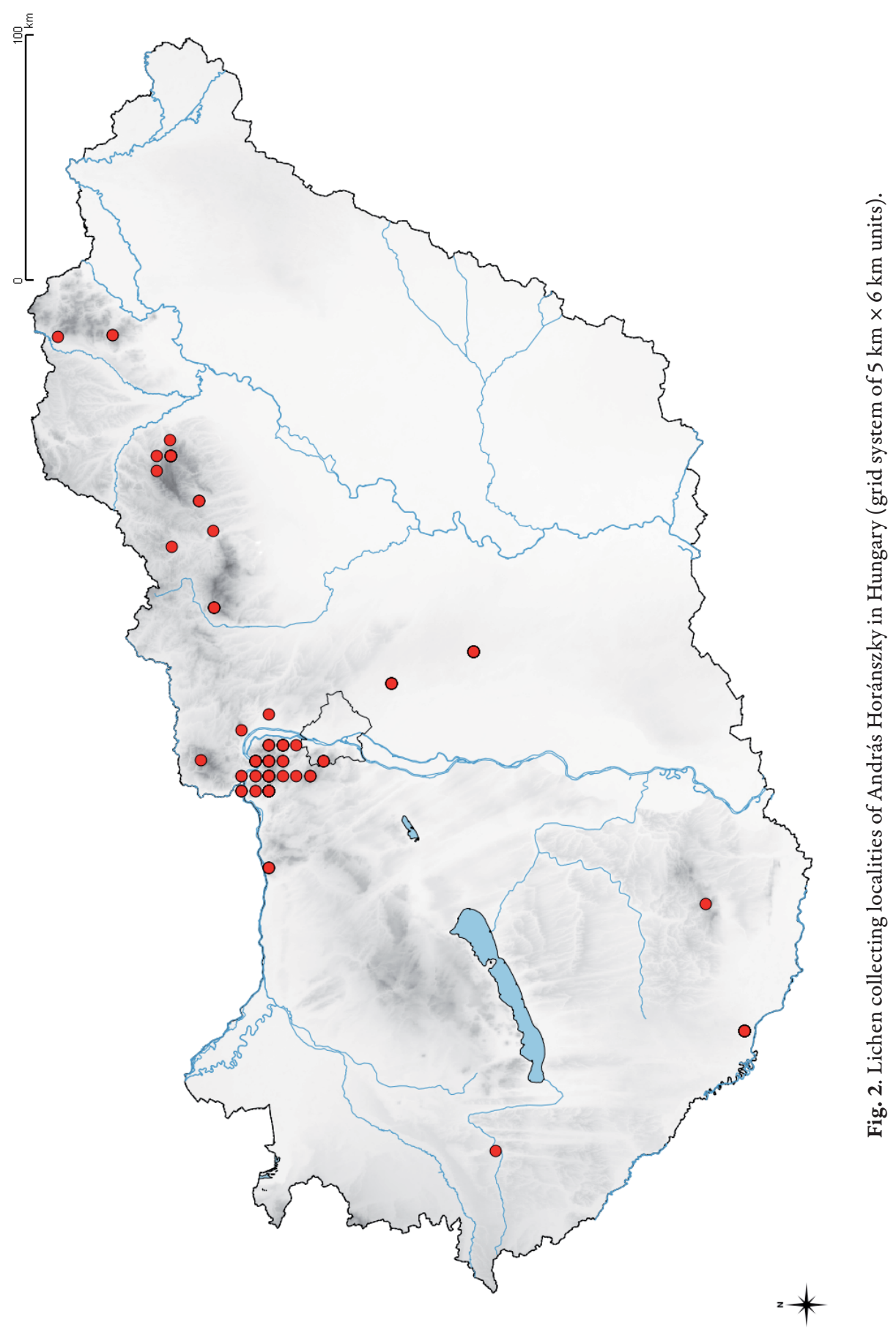

Studia bot. hung. 47(2), 2016 


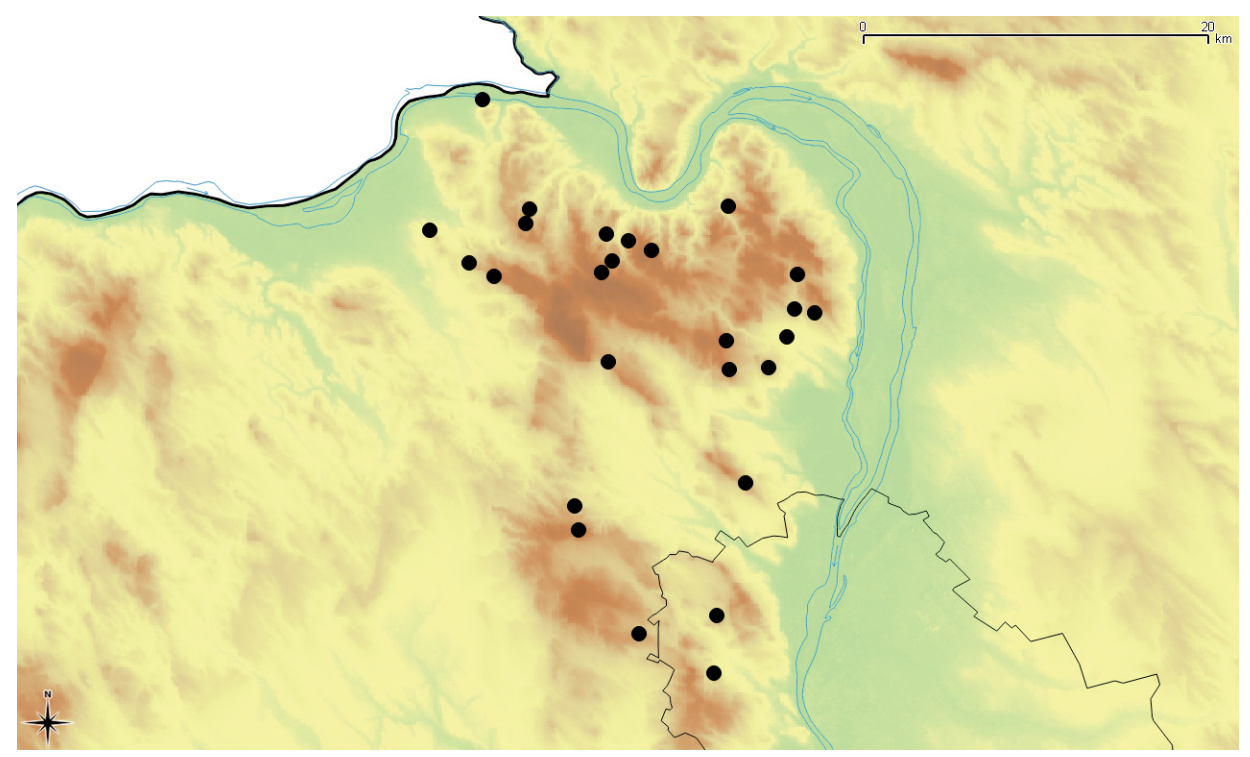

Fig. 3. Lichen collecting localities of András Horánszky in the Pilis-Visegrád Mts.

C. magyarica, C. rangiferina, Usnea florida, and Xanthoparmelia pulvinaris, and two of the lichenicolous fungi Athelia arachnoidea and Xanthoriicola physciae. Agonimia globulifera is new to Hungary.

Acknowledgements - We are grateful to the late András Horánszky, who kindly donated his lichen collection to the Hungarian Natural History Museum. Identification was partly supported by the Hungarian Scientific Research Fund (OTKA K81232).

Összefoglaló: Horánszky András, nyugdíjba vonulását követően, a munkássága alatt gyűjtött zuzmópéldányokat a Magyar Természettudományi Múzeum Növénytárának ajándékozta. A mintegy 250 példányból álló zuzmógyűjteményből több mint 100 zuzmófajt és két zuzmólakó mikrogombafajt tudtunk azonosítani. A gyüjtések elsősorban Magyarország és Ausztria területéről származnak, csupán néhány gyüjtőhely esik Németország, Szerbia és Szlovénia területére. Az eddig publikálatlan adatok számos florisztikai újdonságot rejtenek, többek között törvényesen védett fajok (Cladonia arbuscula, C. magyarica, C. rangiferina, Usnea florida, Xanthoparmelia pulvinaris), illetve zuzmólakó mikrogombafajok (Athelia arachnoidea and Xanthoriicola physciae) szempontjából. Az Agonimia globulifera új adatot jelent Magyarország zuzmóflórájára.

\section{REFERENCES}

Arup, U., Ekman, S., Lindblom, L. and Mattsson, J.-E. (1993): High performance thin layer chromatography (HPTLC), an improved technique for screening lichen substances. Lichenologist 25(1): 61-71. http://dx.doi.org/10.1006/lich.1993.1018 
BorHIDI, A. (1984): Role of mapping the flora of Europe in nature conservation. - Norrlinia 2: $87-98$.

CABI (2016): The Index Fungorum. - http://www.indexfungorum.org (accessed 12 May 2016).

Horánszky, A. (1964): Die Wälder des Szentendre-Visegráder Gebirges. - Akadémiai Kiadó, Budapest, $288 \mathrm{pp}$.

Niklfeld, H. (1971): Bericht über die Kartierung der Flora Mitteleuropa. - Taxon 20(4): 545571. http://dx.doi.org/10.2307/1218258

Orange, A., James, P. W. and White, F. J. (2010): Microchemical methods for the identification of lichens. 2nd ed. - British Lichen Society; London, $101 \mathrm{pp}$.

Robert, V., Stalpers, J. and Stegehuis, G. (2016): MycoBank, the fungal website. - http://www. mycobank.org/DefaultPage.aspx (accessed 15 May 2016).

Simon, T. and Csontos, P. (2016): Horánszky András egyetemi docensre, a biológiai tudományok kandidátusára emlékezünk (1928-2015). (In memoriam András Horánszky, botanist, docent and Candidate of Biological Sciences (1928-2015)). - Bot. Közlem. 103(2): 179-193. http://dx.doi.org/10.17716/BotKozlem.2016.103.2.179

Smith, C. W., Aptroot, A., Coppins, B. J., Fletcher, A., Gilbert, O. L., James, P. W. and Wolseley, P. A. (eds) (2009): The lichens of Great Britain and Ireland. - British Lichen Society, London, $1046 \mathrm{pp}$.

Wirth, V., Hauck, M. and Schultz, M. (2013): Die Flechten Deutschlands. - Verlag Eugen Ulmer, Stuttgart, $1144 \mathrm{pp}$.

(submitted: 30.05 .2016 , accepted: 15.06 .2016 ) 